\title{
Giant congenital nevus: About 3 observations
}

\section{Kaoutar Achehboune, Safae Zinoune, Hanane Baybay, Sara Elloudi, Fatima Zahra Mernissi}

\author{
Department of Dermatology-Venereology, Hospital University, Hassan II, Fez, Morocco
}

Corresponding author: Dr. Kaoutar Achehboune, E-mail: achehboune.kaoutar@gmail.com

\begin{abstract}
Congenital giant naevus (NCG) is a neonatal black tumor, whose diameter is greater than $20 \mathrm{~cm}$. It is a rare pathology affecting 1 to $2 \%$ of newborns. It is present at birth or occurs in the first postnatal weeks it corresponds to a benign proliferation of melanocytes. However the risk of melanoma is estimated at between 2 and $5 \%$ with a poor prognosis in these cases. this is why regular and rigorous clinical and dermoscopic monitoring is essential. The clinical presentation of this tumor is polymorphous with an aesthetic, psychic and sometimes functional impact. The care is difficult and complicated. We report three observations of congenital giant nevi followed in our department.
\end{abstract}

Key words: Giant congenital nevus; Dermoscopie; Children; Melanoma

\section{INTRODUCTION}

Giant congenital nevi (GCN) are benign melanocyte proliferations present at birth or occurring in the first postnatal weeks and with the largest diameter in projected size at adulthood greater than $20 \mathrm{~cm}$. The haunting is the malignant transformation into melanoma; the dermoscopy has an important interest in the monitoring. We illustrate through these observations three cases of infants presenting a giant congenital nevus.

\section{CASE REPORT}

\section{Case 1}

9-month-old male infant from a non-consanguineous first full-term pregnancy with a circumferential, pigmented, trunk-like cupboard, interspersed with a few healthy spaces, associated with pigmented macules scattered on all four limbs and face, with some proliferating nodules in the back, abdomen and scrotum. The diagnosis was that of a giant congenital nevus (Fig. la and lb). The dermoscopic examination found polymorphic aspects: homogeneous pigmentation, homogeneous globular pattern, uniform regular reticular pattern (Fig. 2).

\section{Case 2}

A 17-month-old male infant with no significant pathological history who had had a hyperpilated pigmented, asymptomatic, back-shaped plaque that had not changed in appearance since the birth. Clinical examination revealed a congenital $20 \mathrm{~cm} / 15 \mathrm{~cm}$ nevus in the lower back, associated with similar satellite lesion lesions and others scattered on the lower limbs and trunk, with no proliferating nodules (Fig. 3), with on dermoscopic examination: a homogeneous globular pattern and hypertrichosis.

\section{Case 3}

A 9-year-old female child born in a consanguineous marriage, who had a pigmented cupboard since birth that was of interest to most of the body, with subsequent appearance of multiple similar lesions in the face and limbs. And appearance since 2 years of asymptomatic subcutaneous mass in the left flank (Fig. 4a and 4b). The diagnosis retained after clinical examination was a congenital giant nevus whose dermoscopic examination had objectified the presence of a globular pattern in places and homogeneous by others with hypertrichosis and some aspects in target. The rest of the somatic examination had noted the presence of clitoral hypertrophy.

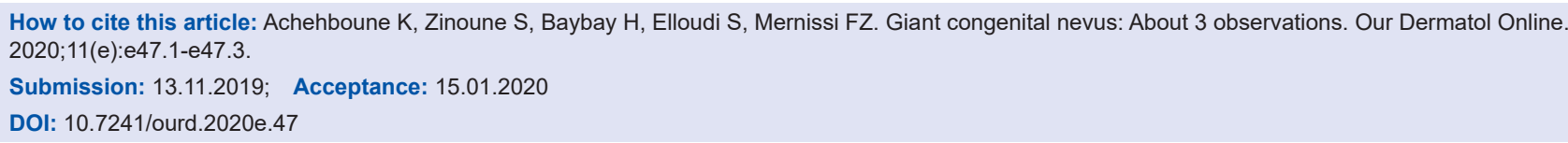




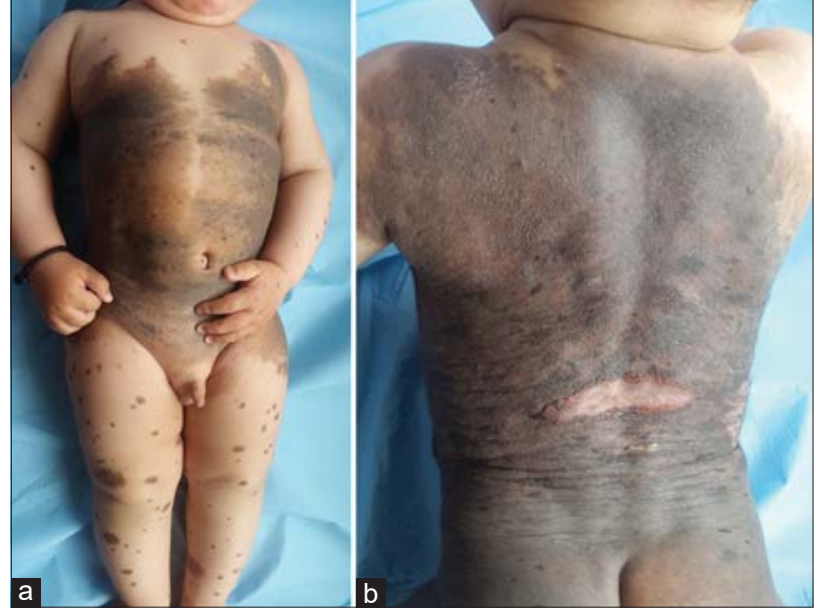

Figure 1: $(a$ and $b)$ Giant congenital nevus interesting the whole trunk with satellite macules on the rest duke body.

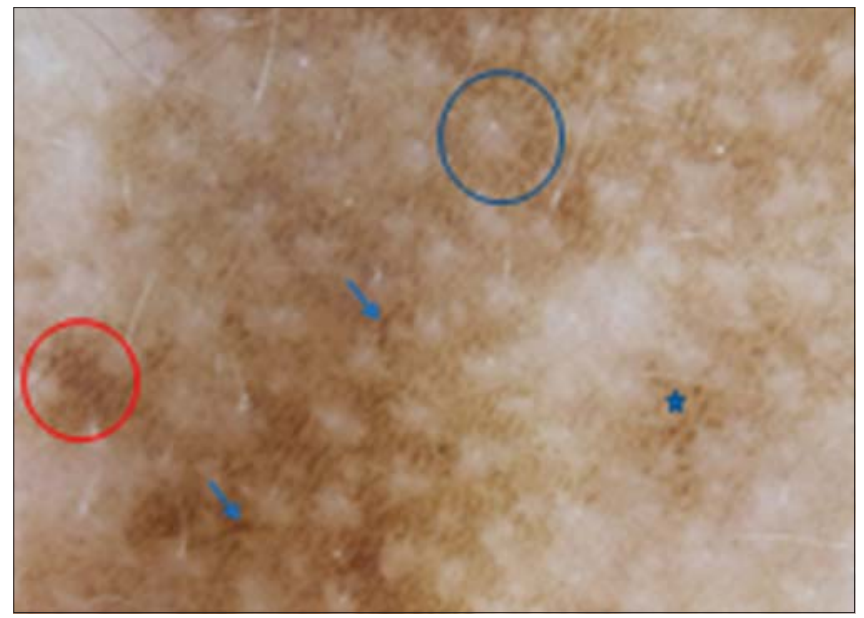

Figure 2: Dermoscopy: blue star - Globules in target; red circle - Homogeneous regular network in target; blue arrow - Focal thickening of the network frame; blue circle - Perifollicular hypopigmentation.

\section{DISCUSSION}

The giant congenital nevi are exceptional; their birth prevalence is estimated at $1 / 50,000$ to $1 / 500,000$ with a slight female predominance. They develop during the first trimester of pregnancy and are due to a neurocristopathy secondary to somatic mutations which are mainly in the NRAS gene [1]. His clinical presentation is polymorphic. Indeed, they are often heterochromatic, raised surface, warty, even nodular, hyperpilous sometimes from the neonatal period and often associated with satellite naevic elements. Their surface may present in the neonatal period erosions or nodular areas that may correspond to proliferation nodules or hamartomatous lesions [2]. The dermoscopic study of GCNs often reveals characteristic elements:

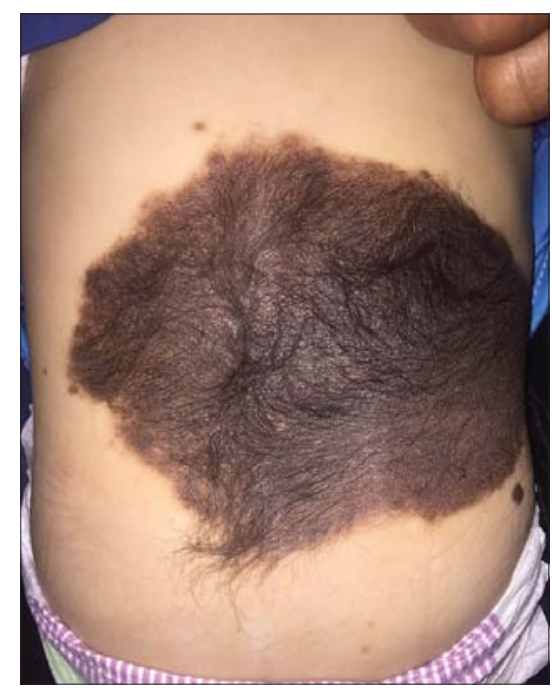

Figure 3: Giant congenital nevus sitting on the lower back.

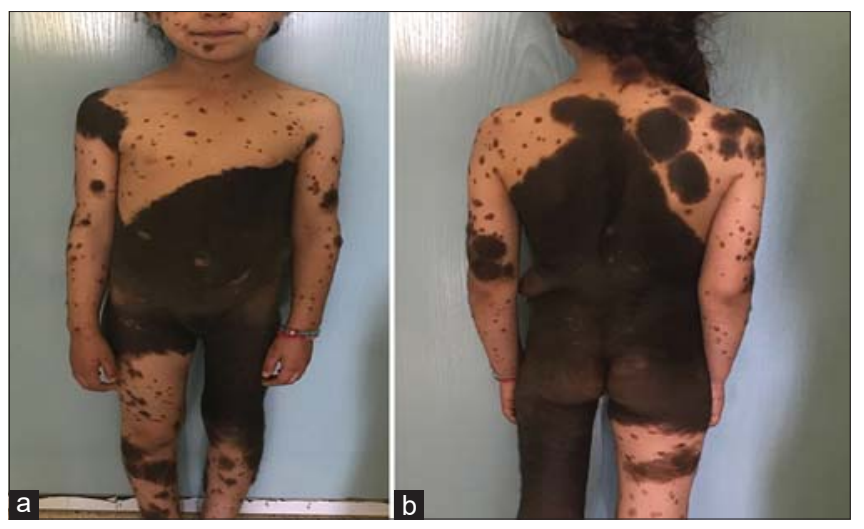

Figure 4: $(a$ and $b)$ Giant congenital nevus interesting the trunk pelvis and thighs with multiple satellite macules on the rest duke body.

appearance of globules in target, network in target, vessels in target, a focal thickening of the network frame or even perifollicular hypopigmentation. These forms seem to be most often associated with complications such as neuropathic disease such as leptomeningeal melanosis, epilepsy, hydrocephalus and a fixed cord, and signs of localization thus indicating the performance of an MRI. But the obsession remains the malignant transformation into melanoma, which is most often of early onset and generally unpleasant prognosis [3]. The treatment of congenital giant nevi is difficult, iterative excisions are proposed, associated with skin expansion techniques [4].

\section{CONCLUSION}

Congenital giant nevi are exceptional, have an unpleasant prognosis and are difficult to manage. Because of their risk of malignant transformation, 
regular clinical and dermoscopic monitoring is required.

\section{Consent}

The examination of the patient was conducted according to the Declaration of Helsinki principles.

The authors certify that they have obtained all appropriate patient consent forms. In the form the patient(s) has/have given his/her/their consent for his/ her/their images and other clinical information to be reported in the journal. The patients understand that their names and initials will not be published and due efforts will be made to conceal their identity, but anonymity cannot be guaranteed.

\section{REFERENCES}

1. Guégan S, Kadlub N, Picard A, Rouillé T, Charbel C, CoulombL'Hermine A, et al. Varying proliferative and clonogenic potential in NRAS-mutated congenital melanocytic nevi according to size. Exp Dermatol. 2016;25:789-96.

2. Lorette G, Le Touze A, Maruan A. Naevus géant congénital. Presse Med. 2013; 42:243-4.

3. Vourc'h-Jourdain M, Martin L, Barbarot S. Large congenital melanocytic nevi: therapeutic management and melanoma risk: a systematic review. J Am Acad Dermatol. 2013;68:493-8.e1-14.

4. Nguyen Van Nuoi V, Francois-Fiquet C, Diner P, SergentaB, ZazurcaaF, Franchia $\mathrm{G}$, et al. Nævus pigmentaires congénitaux géants: quelle place pour l'expansion cutanée. Ann Chir Plast Esthét. 2014;59:240-5.

Copyright by Kaoutar Achehboune, et al. This is an open-access article distributed under the terms of the Creative Commons Attribution License, which permits unrestricted use, distribution, and reproduction in any medium, provided the original author and source are credited.

Source of Support: Nil, Conflict of Interest: None declared. 